Research Article

\title{
Comparative Study of the Mechanical and Water Absorption Behaviour of Basalt Fiber Reinforced Polymer Matrix Composites with Different Epoxies as Matrix for Biomedical Applications
}

\author{
R. Raghavendra Rao $\mathbb{D}^{1},{ }^{1}$ S. Pradeep $\mathbb{D},{ }^{1}$ Nasim Hasan $\left(\mathbb{D},{ }^{2}\right.$ B. S. Shivashankara $\left(\mathbb{D},{ }^{1}\right.$ \\ Mohamed Abdelghany Elkotb $\mathbb{D}^{3,4}$ C. Ahamed Saleel $\mathbb{D}^{3},{ }^{3}$ Asif Afzal $\mathbb{D}^{5,6}$ and B. Saleh $\mathbb{D}^{7}$ \\ ${ }^{1}$ Department of Mechanical Engineering, Malnad College of Engineering, (Affiliated to Visvesvaraya Technological University, \\ Belagavi), Hassan, Karnataka, India \\ ${ }^{2}$ Mechanical Engineering Department, Mettu University, Mettu Oromia, P.O. Box 318, Ethiopia \\ ${ }^{3}$ Department of Mechanical Engineering, College of Engineering, King Khalid University, PO Box 394, Abha 61421, Saudi Arabia \\ ${ }^{4}$ Mechanical Engineering Dept., Faculty of Engineering, Kafrelsheikh University, Kafr el-Sheikh, Egypt \\ ${ }^{5}$ Department of Mechanical Engineering, P. A. College of Engineering, \\ Mangalore (Affiliated to Visvesvaraya Technological University, Belagavi 574153, Karnataka, India \\ ${ }^{6}$ Department of Mechanical Engineering, School of Technology, Glocal University, Delhi-Yamunotri Marg, SH-57, Mirzapur Pole, \\ Saharanpur District, Uttar Pradesh-247121, India \\ ${ }^{7}$ Mechanical Engineering Department, College of Engineering, Taif University, P.O. Box 11099, Taif 21944, Saudi Arabia
}

Correspondence should be addressed to Nasim Hasan; nasim.hasan@meu.edu.et

Received 9 August 2021; Accepted 17 November 2021; Published 22 December 2021

Academic Editor: Ravichandran M

Copyright (c) 2021 R. Raghavendra Rao et al. This is an open access article distributed under the Creative Commons Attribution License, which permits unrestricted use, distribution, and reproduction in any medium, provided the original work is properly cited.

\begin{abstract}
In comparison to conventional materials, polymer matrix composite materials have witnessed a surge in applicability due to their higher specific strength-to-weight ratio, abundant availability, and ease of shaping. Due to technological, economic, environmental, and societal challenges, bio-based fibers began to emerge quickly for use in industrial components. Due to its unique chemistry-related characteristics, basalt fiber holds a prominent position among the many bio-based fibers. So, it could be thought of used as a replacement for some components used in the biomedical equipments. In the present investigation, plain-woven basalt fiber at a constant percentage of $55 \%$ is added as reinforcement to three different epoxy resin-hardener combinations such as Lapox L12-Lapox K6, Araldite LY1564-Aradur 22962, and Araldite LY556-Aradur HY951 as matrix, and comparative studies are carried out. Fabrication is carried out by hand lay-up technique. Test specimens are prepared as per the respective ASTM standards by subjecting the laminate to water jet machining. Mechanical characterization such as tensile, flexural, and density tests is conducted for the test specimen using BISS-50 kN Universal Testing Machine (UTM). Water absorption tests are also conducted for 24 and 48 hours duration. From the results obtained, it is concluded that the highest tensile, flexural strengths are obtained for laminate L3 which used LY556 epoxy and HY951 hardener combination as matrix. Also, less rate of water absorption is seen for L3 laminate for both 24 and $48 \mathrm{hrs}$ which makes it suitable for biomedical applications.
\end{abstract}

\section{Introduction}

Polymer matrix composites offer a wide range of uses due to its superior strength-to-weight ratio, corrosion resistance, less weight, adaptability, shape ability, and suitability for a variety of technical applications. Although polymer matrix composites (PMCs) were first used in the early twentieth century, they were only widely used in the 
second half of the century. Basalt is a clean and environmentally benign substance that originates from volcanic rocks and has a melting temperature of $1500^{\circ} \mathrm{C}$ to $1700^{\circ} \mathrm{C}[1,2]$. The density of basalt fibers ranges between $2.7 \mathrm{~g} / \mathrm{cc}$ and $2.8 \mathrm{~g} / \mathrm{cc}$. It is extremely hard compared with some conventional materials and has higher abrasion resistance [3]. It is stated that the basalt fiber could be a possible alternative compared with natural plant fibers [4]. Czigany [5] proved that the basalt could be considered as natural fiber. It is chemically inert and could be a major breakthrough as bio material. Dhand et al. [6] have considered that despite their severe mechanical qualities, basalt fiber resources are widely available around the world. They could be manufactured using a low-energy process at a lower cost than glass and, more specifically, carbon strands. They are created by spinning liquid volcanic basalt rock through a spinning cycle. This cycle is similar to that of making glass strands. However, in case of the basalt, no additional substances are required. This reduces the risk of the piece being exposed to poisonous substances. As a result, the manufacturing process is more environmentally friendly $[7,8]$. Basalt fibers are more chemically stable and have a very strong corrosion resistance [9]. The major constituent of basalt is $\mathrm{SiO}_{2}$ (42-56\% by weight), $\mathrm{Al}_{2} \mathrm{O}_{3}$ (14-18\%), $\mathrm{Fe}_{2} \mathrm{O}_{3}$ (11-12\%), $\mathrm{CaO}$ (7-9\%), and other oxides (refer Figure 1) [10]. Raghavendra Rao et al. [11] have undergone a study of UHMWPE/basalt reinforced hybrid polymer matrix composite. They have concluded that the inclusion of UHMWPE fibers has increased the flexural strength considerably. Fiore et al. [12] investigated the effect of uniaxial basalt fiber on the mechanical properties of a glass fiber/epoxy composite (GFRP) intended for marine use. The presence of two outer layers of basalt in comparison to GFRP laminates has resulted in improved mechanical properties of the fabricated laminates. Lilli et al. [13] studied the effect of low temperature plasma polymerization on the interfacial behaviour of basalt fiber reinforced polymer matrix composites. A polymer coating based on pure tetra vinyl silane (TVS) or its combination with two different oxygen levels was deposited on the surface of an unsized basalt fiber using plasma-assisted chemical vapour deposition. The impact of the plasma procedure was initially investigated using a single fiber tensile test characterization, which revealed that the changed fibers had no loss of strength. Following that interfacial strength was investigated using single fiber pullout tests with an epoxy matrix. When compared with untreated basalt fibers, the addition of oxygen to the polymer film combination has shown increased interfacial shear strength (IFSS) by $79 \%$. Many studies have previously concentrated on improving the interface for synthetic fibers, particularly glass and carbon fibers, while basalt fibers have received less attention. Goudar Santosh Gangappa and S. Sripad Kulkarni [14] have experimented and validated basalt and jute fiber reinforced hybrid polymer matrix composites. Polymer hybrid composites are created using compression moulding techniques, with polyester resin as the matrix and basalt and jute as

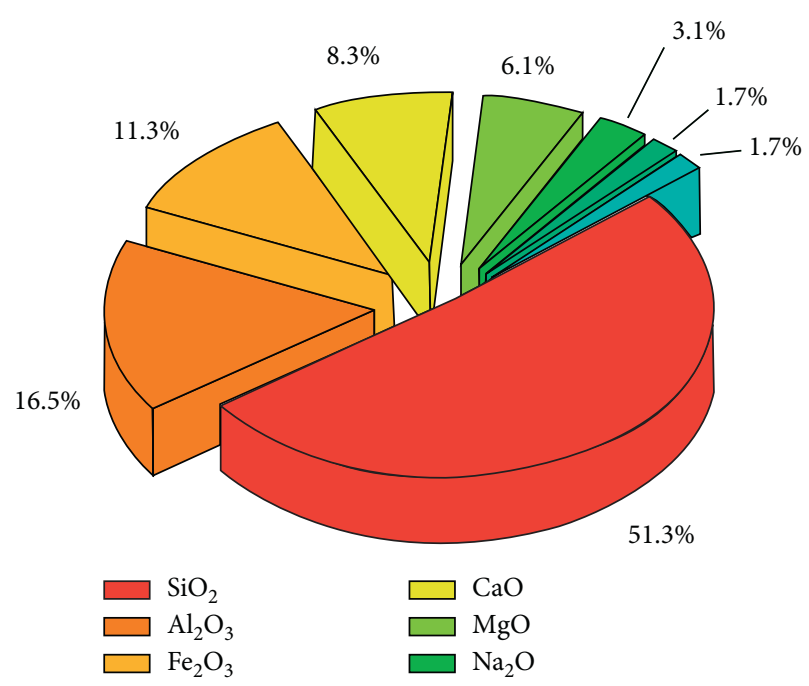

Figure 1: Chemical composition of basalt fiber [10].

reinforcement. The static and dynamic behaviours are studied. It is revealed that the hybrid laminates had better damping ratio and hence could be used as vibration absorbing materials. Xing Zhao et al. [15] investigated the effect of different resin matrices on static and fatigue loading conditions in basalt fiber reinforced polymer composites. Four different types of resins were used in their study. Normal and toughened vinyl ester resins, as well as room and elevated temperature curing epoxy systems, were used. The scanning electron microscopy (SEM) system embedded in the fatigue test equipment was used to perform fractography of failed surfaces in parallel with the static and fatigue tests. The static tensile strength of the BFRP with normal vinyl ester resin was comparable with that of the BFRP with elevated temperature cured epoxy, according to the results. However, due to more matrix cracking and fiber peeling on the surface of the vinyl ester resin-based BFRP, the former had a significantly shorter fatigue life than the latter. However, the former had a significantly shorter fatigue life than the latter due to more matrix cracking and fiber peeling on the surface of the vinyl ester resin-based BFRP. Siwon Yu et al. [16] have studied the effect of plasma polymerization to improve the interfacial bonding strength and hence its effect on the mechanical properties of the developed BFRP. The former had exhibited significantly shorter fatigue life than the latter due to more matrix cracking and fiber peeling on the surface of the vinyl ester resin-based BFRP. However, due to more matrix cracking and fiber peeling on the surface of the vinyl ester resin-based BFRP, the former had a significantly shorter fatigue life than the latter. The results showed that APTES plasma-polymerized $\mathrm{BF}$ produced a robust interface with a 50.3 percent increase in interfacial shear strength and a 32.5 percent increase in tensile strength when compared with untreated BF. On the BF surface, the APTES was plasma polymerized for $3,5,7$, and 9 minutes. The mechanism of reaction during plasma polymerization was investigated and compared with a traditional solution dipping method. 
According to the available literature, no research articles have reported the comparative evaluation of the effect of various epoxies on the mechanical and water absorption behaviours of BFRP composites. An effort is made in this direction from the point of view of biomedical applications.

\section{Materials and Methods}

2.1. Materials. Reinforcement used in the present investigation is basalt plain-woven fabric of 300 GSM. Details of fabrics are illustrated in Table 1. The epoxy resin and hardener combinations used are shown in Table 2.

2.2. Fabrication of Composites. Hand lay-up approach was used for the fabrication of laminates. First, the basalt fabrics were cut to the dimensions of $300 \times 300 \mathrm{~mm}^{2}$. Then, laminates are prepared using 10 layers of fabric to maintain approximate thickness of $3 \mathrm{~mm}$ for different epoxy-hardener combinations as indicated in Table 2. The epoxy resin and hardener were mixed in the ratio of $100: 10$ by weight. First, wax was applied over the top of a mould, and then the fabric layers were laid one over another in the mould, simultaneously applying the measured quantity of epoxy on each layer of the fabrics. Then, the epoxy was uniformly spread using roller. As soon as the last layer of fiber was properly rolled, the toughened glass slab of required size was kept on top of the mould. On the top of the glass slab, dead weights are placed and sustained in that spot for 24 to 48 hours and then withdrawn. The laminates $L 1$ and $L 2$ are cured in oven for a temperature range of 60 to $80^{\circ} \mathrm{C}$ for 2 hours, but the laminate $L 3$ is cured at the room temperature. Then, the test samples were prepared using water jet machining as per the ASTM standards.

2.3. Density Test. For a sample of $10 \mathrm{~mm} \times 10 \mathrm{~mm} \times 3 \mathrm{~mm}$, the mass " $m$ " is weighed on a precision weighing scale. The volume " $V$ " of the sample is determined using the Archimedes principle. A $100 \mathrm{ml}$ beaker is partially filled with distilled water. The initial water level " $V_{1}$ " is noted at lower level of the meniscus. The samples are then dipped one by one to determine the ultimate or final water level " $V_{2}$." The sample volume " $V$ " is calculated by subtracting the initial water level " $V_{1}$ " from the final water level " $V_{2}$."

Therefore, $V=V_{2}-V_{1}$. Then, the density of a material is calculated using the formula as follows:

$$
\rho=\frac{m}{V} \text { grams } / \mathrm{cm}^{3},
$$

where " $m$ " is the mass of the sample in grams and " $V$ " is the volume of the sample in $\mathrm{cm}^{3}$.

2.4. Water Absorption Test. According to the ASTM D570 standard, water absorption tests are performed for 24 and 48 hours duration. The initial weight " $W_{1}$ " of a sample size of $10 \times 10 \times 3 \mathrm{~mm}^{3}$ is determined. Then, it is steeped for 24 hours in distilled water inside a beaker. It is extracted after 24 hours, and its final weight " $W_{2}$ " is determined. The water
TABLE 1: The basic properties of basalt fabrics used.

\begin{tabular}{lcc}
\hline Parameters & Value & ASTM \\
\hline Density (g/cc) & $2.77-2.80$ & ASTM D3800 \\
Weight (GSM) & 300 & - \\
Thickness (mm) & 0.25 & - \\
Melting point & $1500-1700^{\circ} \mathrm{C}$ & ASTM D276 \\
Tensile strength $(\mathrm{MPa})$ & $1800-4100$ & ASTM D2256 \\
Modulus of elasticity $(\mathrm{GPa})$ & $96-100$ & ASTM C169 \\
\hline
\end{tabular}

absorption weight percentage is calculated using the formula as follows:

$$
\text { water absorption weight } \%=\frac{W_{2}-W_{1}}{W_{1}} \times 100 \% \text {. }
$$

By dipping the samples for 48 hours duration, the same procedure is repeated.

2.5. Tensile Test. The tensile test was performed with data capture software on a BISS-50 kN capacity Universal Testing Machine (UTM). The sample $\left(115 \times 19 \times 3 \mathrm{~mm}^{3}\right)$ was chosen according to the ASTM: D638-IV standard, with a gauge length of $33 \mathrm{~mm}$ and a crosshead speed of $1.0 \mathrm{~mm} / \mathrm{min}$, and the test was carried out at room temperature. The results obtained are used to plot the respective graphs.

2.6. Flexural Test. 3-point bending test is conducted as per the ASTM: D790 standard using the same UTM. Testing was conducted at loading rate of $2.0 \mathrm{~mm} / \mathrm{min}$, at room temperature. The dimension of the specimen is $90 \times 12.5 \times 3 \mathrm{~mm}^{3}$, and the flexural specimens were fixed between two jaws with a gauge length of $60 \mathrm{~mm}$, and the load was applied at the center. Loading is applied to the specimen until it ruptures. The flexural strength and modulus are obtained with the help of data acquisition software.

2.7. Surface Morphology. Fractured tensile specimens were examined for microstructure using TESCAN-VEGA 3 LMU scanning electron microscope. SEM was carried out to visualize the dispersion of fibers within the matrix and the adhesion characteristics amongst fiber and matrix. In order to enhance the conductivity of the samples, the surface of the sample was coated with a thin gold film and the micrographs were captured from the fractured samples for different magnifications.

\section{Results and Discussion}

3.1. Density Test. Figure 2 depicts the experimental values of densities for the prepared composite laminates. Minute difference in experimental densities was observed amongst of the laminates since they are only with varied epoxyhardener combinations but prepared for a constant fiber percentage of $55 \%$ as shown in Figure 2. The L3 laminate exhibited the maximum density of $1.78 \mathrm{~g} / \mathrm{cc}$, the $L 2$ laminate exhibited the lowest density of $1.71 \mathrm{~g} / \mathrm{cc}$, and laminate $L 1$ exhibited a density of $1.73 \mathrm{~g} / \mathrm{cc}$. 
Table 2: Properties of different epoxy-hardener combinations.

\begin{tabular}{|c|c|c|c|c|c|c|}
\hline Laminate & $\begin{array}{l}\text { Epoxy-hardener } \\
\text { combination }\end{array}$ & $\begin{array}{c}\text { Epoxy density at } \\
25^{\circ} \mathrm{C} \text { in } \mathrm{g} / \mathrm{cc} \\
(\mathrm{ISO} 1675)\end{array}$ & $\begin{array}{c}\text { Hardener density } \\
\text { at } 25^{\circ} \mathrm{C} \text { in g/cc (ISO } \\
1675 \text { ) }\end{array}$ & $\begin{array}{c}\text { Epoxy viscosity at } \\
25^{\circ} \mathrm{C} \text { in } \mathrm{MPa} \text { s (ISO } \\
12058-1 \text { ) }\end{array}$ & $\begin{array}{c}\text { Hardener viscosity at } \\
25^{\circ} \mathrm{C} \text { in } \mathrm{MPa} \text { s (ISO } \\
12058-1 \text { ) }\end{array}$ & $\begin{array}{c}\text { Curing conditions } \\
\text { used }\end{array}$ \\
\hline$L 1$ & $\begin{array}{c}\text { Lapox L12- } \\
\text { hardener K6 }\end{array}$ & 1.120 & 0.954 & $9000-12000$ & $5000-8000$ & $80^{0} \mathrm{C}$ for $1-2 \mathrm{hrs}$ \\
\hline$L 2$ & $\begin{array}{l}\text { Araldite LY1564- } \\
\text { Aradur } 22962\end{array}$ & 1.1 to 1.2 & $0.89-0.90$ & $1200-1400$ & $5-20$ & $80^{0} \mathrm{C}$ for $1 \mathrm{hr}$ \\
\hline$L 3$ & $\begin{array}{c}\text { Araldite LY556- } \\
\text { Aradur HY951 }\end{array}$ & 1.1 to 1.2 & 0.980 & $1350-2000$ & $10-20$ & $\begin{array}{c}\text { Room temperature } \\
\left(25^{\circ} \mathrm{C} \text { for } 24 \text { to }\right. \\
48 \mathrm{hrs})\end{array}$ \\
\hline
\end{tabular}

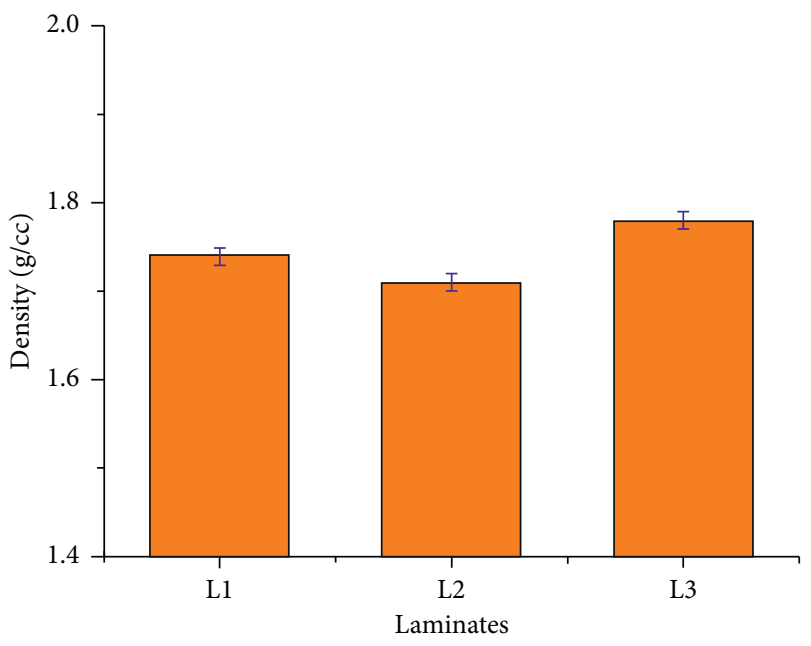

Figure 2: Representation of densities of different laminates.

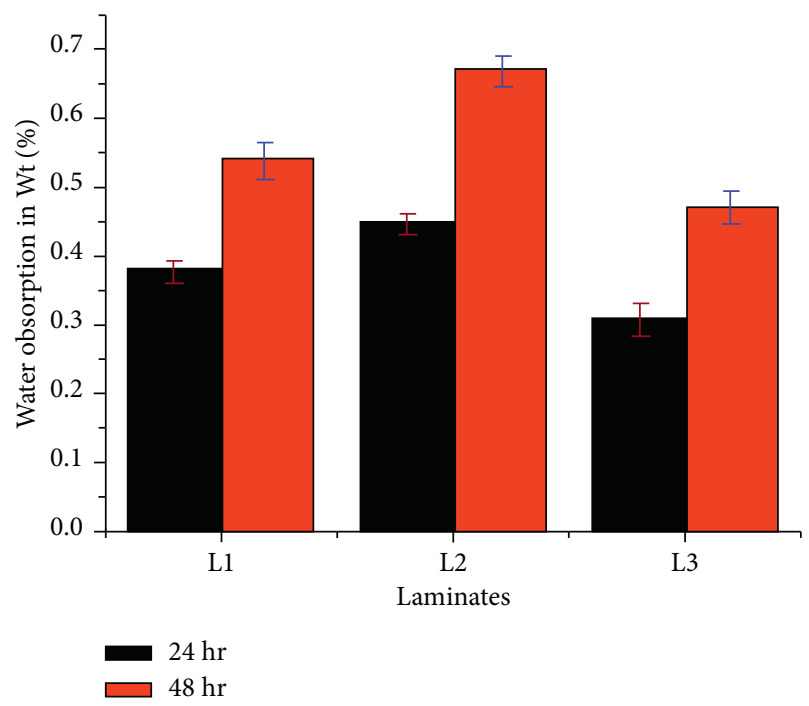

FIGURE 3: Representation of water absorption comparative plot.

3.2. Water Absorption Test. Figure 3 depicts the water absorption percentages of different laminates. For both 24 and 48 hours, laminate $L 3$ exhibited the least water absorption percentage of $0.31 \%$ and $0.47 \%$, respectively. The laminate L2 exhibited the highest water absorption percentage of
$0.45 \%$ and $0.67 \%$, respectively. Similarly, laminate $L 1$ exhibited the moderate water absorption percentage of $0.37 \%$ and $0.54 \%$ for 24 hours and 48 hrs, respectively. In first 24 hours, all the laminates show a higher rate of water absorption, while in the next 24 hours they had shown a lesser rate of water absorption.

3.3. Tensile Property Evaluation. Figures 4 and 5 illustrate the tensile strength and modulus of different laminates, respectively. The laminate $L 3$ had the maximum tensile strength and modulus, while the laminate $L 2$ had the least tensile strength and modulus, as shown in the figure. The composite laminate $L 3$ exhibited highest tensile strength and modulus of $304.36 \mathrm{MPa}$ and $10.41 \mathrm{GPa}$, respectively, and L2 laminate exhibited the least tensile strength and modulus of $143.8 \mathrm{MPa}$ and $5.1 \mathrm{GPa}$, respectively. The laminate $L 1$ exhibited moderate tensile strength and modulus of 210.5 $\mathrm{MPa}$ and $9.1 \mathrm{GPa}$, respectively. Figure 6 demonstrates the mode of failure and fiber pullout happening during the tensile test. As seen from Figures 6(a) and 6(b) for laminates $L 1$ and $L 2$, respectively, the fiber pullout is occurring inappropriately. The fabric layers are peeled out during tensile testing, which indicates that the fiber-matrix adhesions are very low. Figure 6(c) depicts the tensile tested sample for laminate L3, which clearly shows the good fiber-matrix adhesion characteristics and appropriate fiber breakage and pullout.

3.4. Flexural Property Evaluation. Figures 7 and 8 illustrate the flexural strength and modulus, respectively. The laminate $L 3$ exhibited the highest flexural strength and modulus, while the laminate $L 2$ exhibited the lowest flexural strength and modulus [17-20]. The composite laminate $L 3$ exhibited highest flexural strength and modulus of $318.8 \mathrm{MPa}$ and $12.18 \mathrm{GPa}$, respectively, and laminate $L 2$ exhibited lowest flexural strength of $151.1 \mathrm{MPa}$ and modulus of $6.41 \mathrm{GPa}$, respectively. The laminate $L 1$ exhibited moderate flexural strength and modulus of $220 \mathrm{MPa}$ and $10.2 \mathrm{GPa}$, respectively. Figures 9(a)-9(c) show the flexural tested samples for $L 1, L 2$, and $L 3$ laminates, respectively.

The present research revealed that the ultimate tensile strength, tensile modulus, flexural strength, and flexural modulus were seen maximum for L3 laminate [21-25]. Also, least water absorption percentage is seen for L3 laminate. 


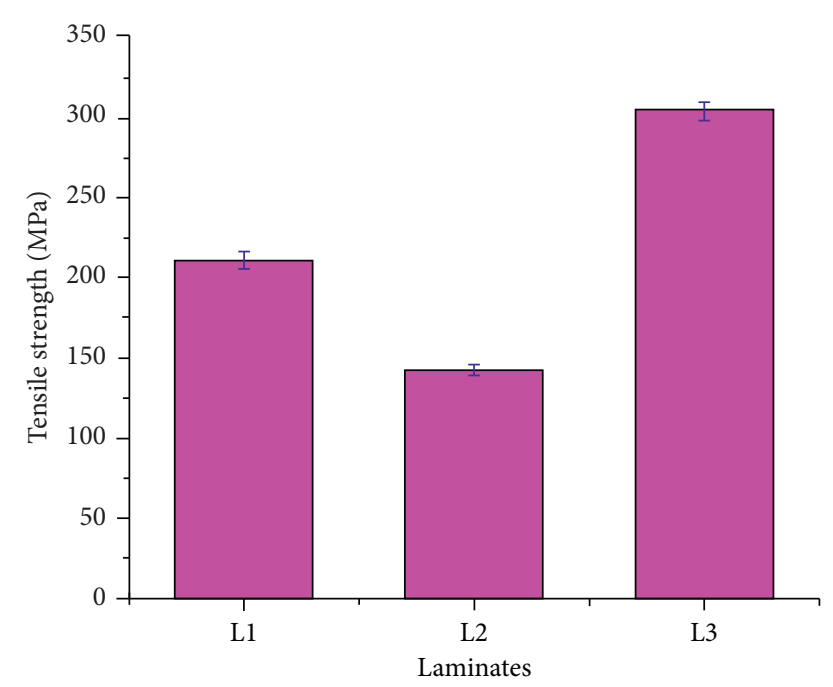

FIGURE 4: Representation of tensile strengths of different laminates.

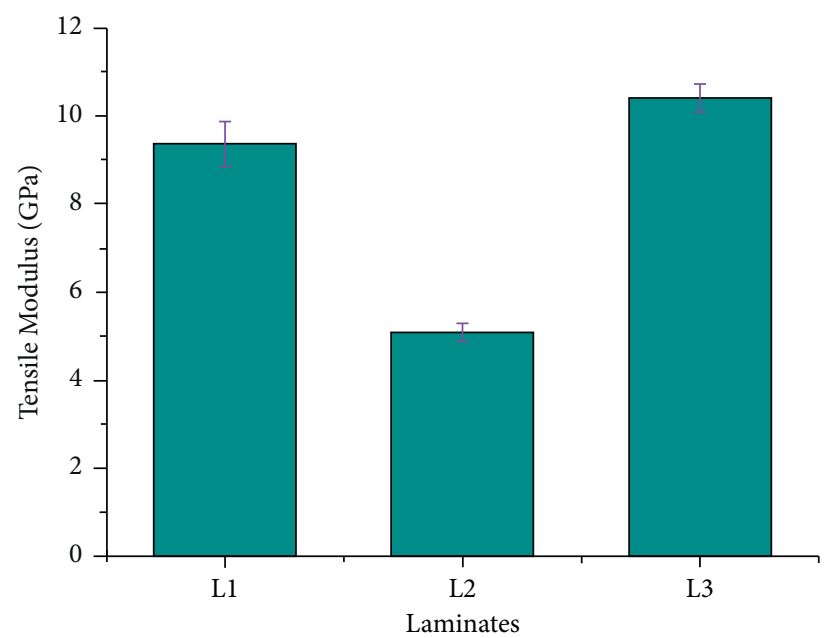

Figure 5: Representation of tensile modulus of different laminates.

3.5. Morphological Studies through SEM. Microstructural studies were conducted to visualize the failure surfaces of the fabricated laminates subjected to tensile loading. The fracture in the tested samples takes place due to the application of uniaxial tensile loading. The void content, fiber-matrix adhesion, and pullout properties are analyzed using the SEM images. All the composite specimens were coated with gold before observing them through SEM. The fractured micrographs of various laminate designations $L 1, L 2$, and $L 3$ are shown in Figures 10(a)-10(c), respectively. It is seen that the fiber filaments are almost completely covered with an epoxy system. It showed (Figures 10(a)-10(c)) fewer amounts of voids in the fractured samples of laminates except L3 laminate. Not much interfacial deboning, matrix cracking and delamination were observed in the case of $L 3$ laminate. It is evident from Figures 10(a) and 10(b) that the presence of voids, matrix cracking, fiber pullouts, and delamination is predominant in the case of laminates $L 1$ and L2. Comparatively, L3 laminates had lesser amount of voids and cracks than other laminates, which helped to get better 


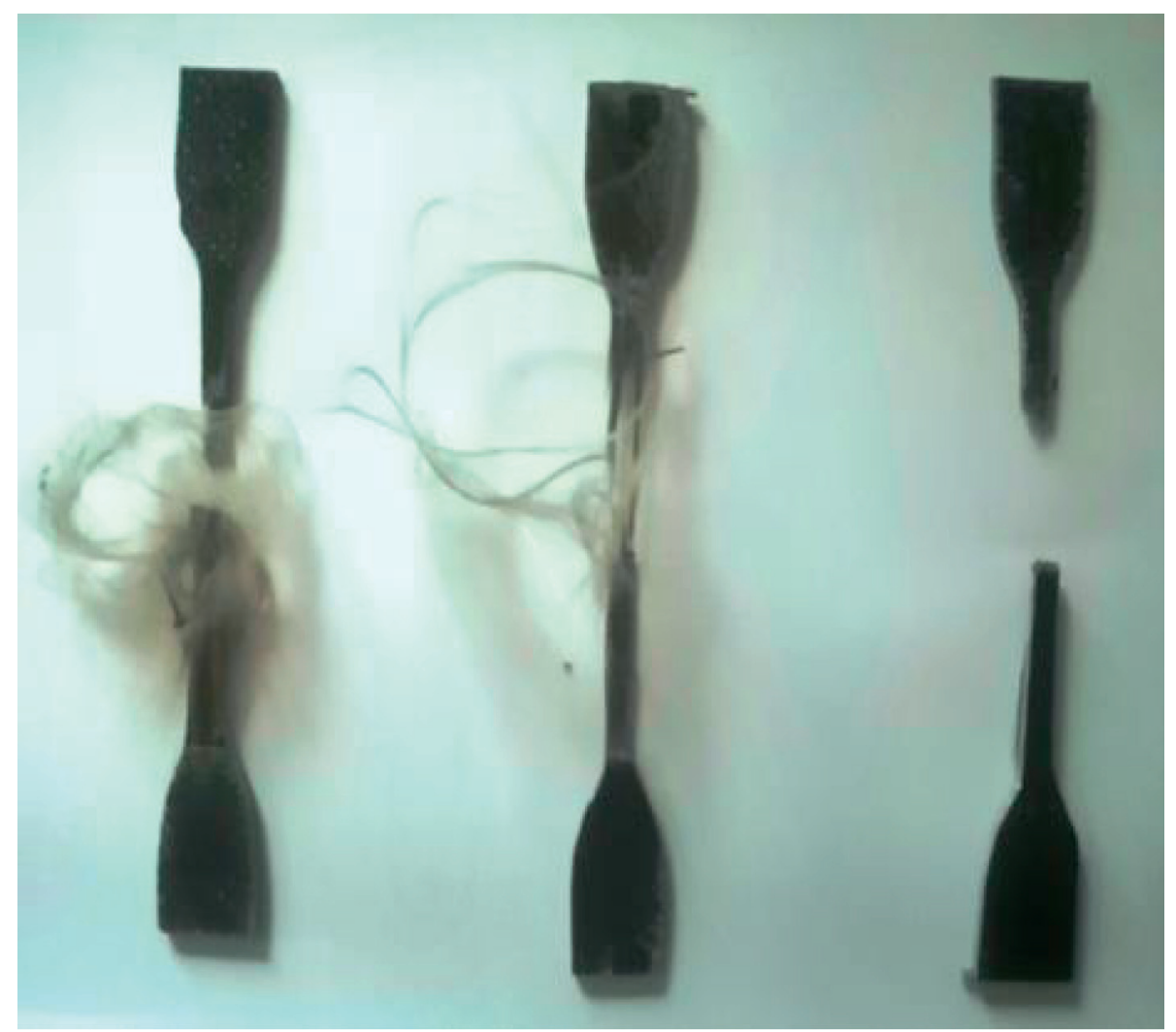

Figure 6: Representations of tensile tested samples for (a) laminate L1; (b) laminate L2; (c) laminate L3.

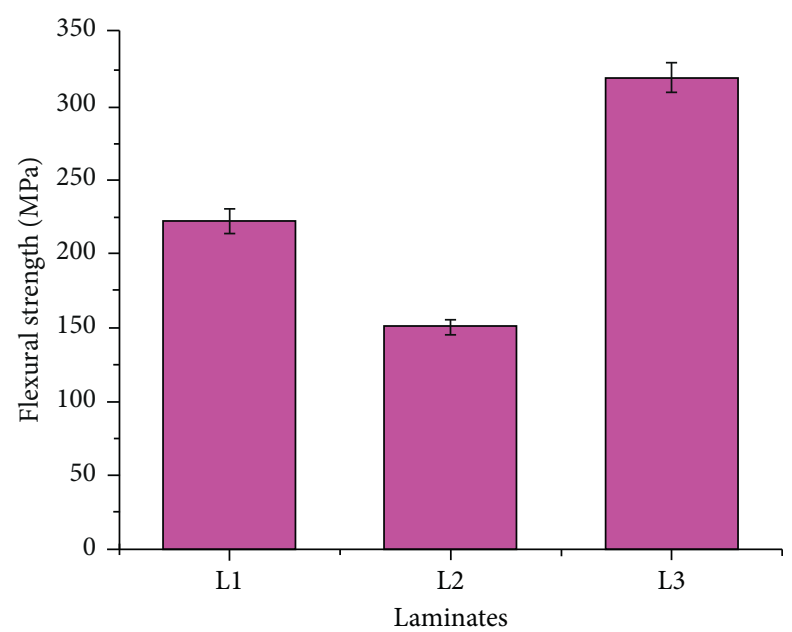

Figure 7: Representation of flexural strengths of different laminates. 


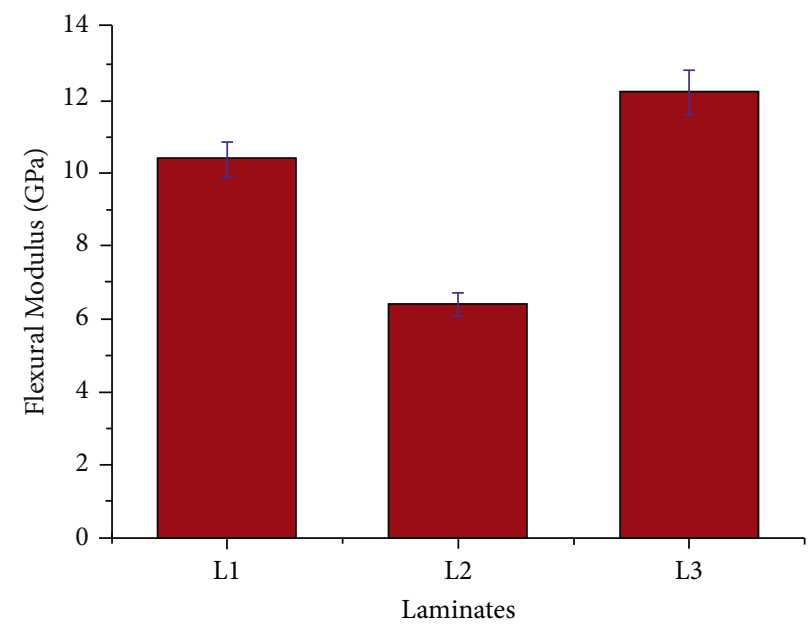

Figure 8: Representation of flexural modulus of different laminates.
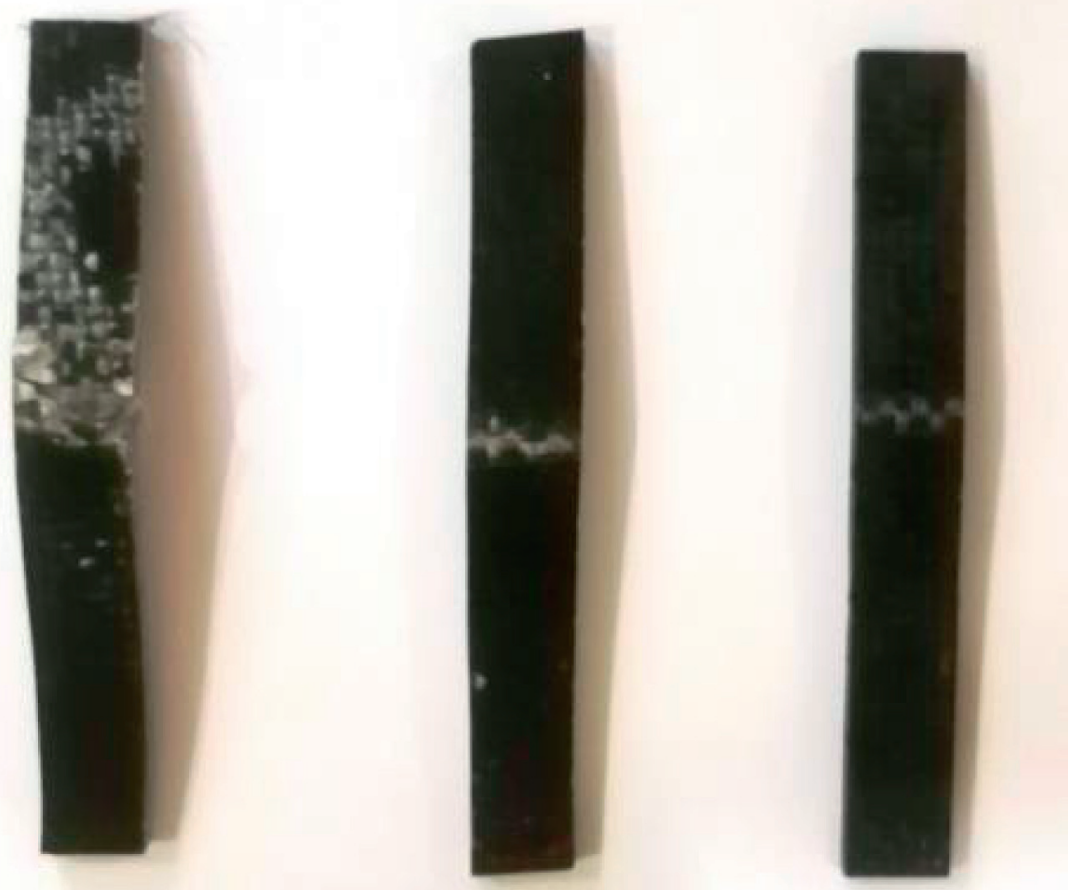

FIgURE 9: Representations of flexural tested samples for (a) L1 laminate; (b) L2 laminate; (c) L3 laminate.

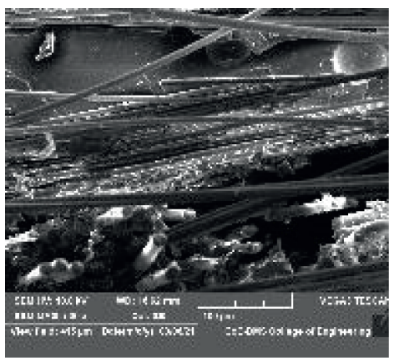

(a)

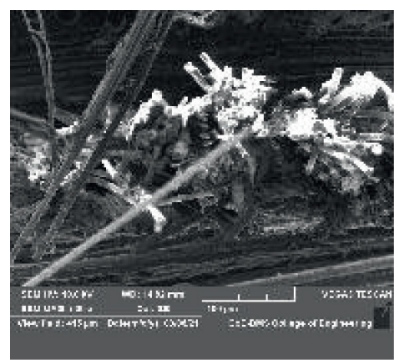

(b)

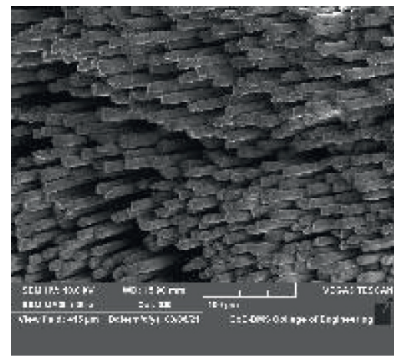

(c)

FIgURE 10: SEM images of tensile tested samples for (a) L1 laminate; (b) L2 laminate; (c) L3 laminate. 
mechanical properties and improved adhesion amongst the fibers and matrix.

\section{Conclusions}

Effect of three different epoxy resins on the water absorption and mechanical properties of plain-woven basalt fiber reinforced polymer matrix composites was studied for 55 wt.\%. The following conclusions were drawn based on the present experimental results:

(i) The composite laminate $L 3$ shows highest tensile strength and modulus of $304.36 \mathrm{MPa}$ and $10.41 \mathrm{GPa}$ and $L 2$ laminate shows the least tensile strength and modulus of $143.8 \mathrm{MPa}$ and $5.1 \mathrm{GPa}$.

(ii) The composite laminate L3 indicated highest flexural strength and modulus of $318.8 \mathrm{MPa}$ and $12.18 \mathrm{GPa}$ and laminate $L 2$ indicated lowest flexural strength of $151.1 \mathrm{MPa}$ and modulus of $6.41 \mathrm{GPa}$.

(iii) The nonhybrid L3 laminate exhibited highest density of $1.78 \mathrm{~g} / \mathrm{cc}$ and the $L 2$ laminate exhibited the least density of $1.71 \mathrm{~g} / \mathrm{cc}$.

(iv) Laminate $L 2$ exhibited highest water absorption percentage of $0.45 \%$ and $0.67 \%$ and the laminate $L 3$ exhibited least water absorption percentage of $0.31 \%$ and $0.47 \%$ for 24 and 48 hours, respectively.

(v) Failure pattern confirmed that the L3 composite laminates showed better adhesion between fibers and matrix, appropriate fiber breakage, and pullout. Also, better mechanical properties and least water absorption are observed for laminate L3. So, it is suggested to go with the LY556-HY951 epoxy hardener combination as a matrix for the basalt fiber reinforced polymer composites.

(vi) SEM analysis confirmed that the L3 composite laminates showed lesser voids, better adhesion between fibers and matrix, appropriate fiber breakage, and pullout.

(vii) Good water absorption behaviour and mechanical strengths are seen which make the composite developed to be used for biomedical applications.

\section{Data Availability}

The data used to support this study are available upon request.

\section{Conflicts of Interest}

The authors declare that there are no conflicts of interest regarding the publication of this article.

\section{Acknowledgments}

The authors extend their appreciation to the Deanship of Scientific Research at King Khalid University, Saudi Arabia, for funding this work through the Research Group Program under Grant No. RGP 2/108/42. This study was supported by
Taif University Researchers Supporting Project number (TURSP-2020/49), Taif University, Taif, Saudi Arabia. The authors would like to thank Taif University for financial support. This study was supported by TEQIP III, MCE, Hassan. The authors would like to thank Malnad College of Engineering, Hassan, for financial support.

\section{References}

[1] J. Militký, V. R. Kovačič, and J. Rubnerova, "Influence of thermal treatment on tensile failure of basaltfibers," Engineering Fracture Mechanics-Journals, vol. 69, pp. 1025-1033, 2002.

[2] J. Militky and V. Kovacic, "Ultimate mechanical properties of basalt filaments," Textile Research Journal, vol. 66, no. 4, pp. 225-229, 1996.

[3] M. Di Ludovico, A. Prota, and G. Manfredi, "Structural upgrade using basalt fibers for concrete confinement," Journal of Composites for Construction, vol. 14, no. 5, pp. 541-552, 2010.

[4] T. Tabi and J. Kovacs, "Examination of starch pre-process drying and water absorption on injection moulded poly (lactic acid)/starch blends," Polymer Engineering \& Science, vol. 51, pp. 843-850, 2011.

[5] T. Czigány, "Basalt fiber reinforced hybrid polymer composites," Materials Science Forum, vol. 473-474, pp. 59-66, 2005.

[6] V. Dhand, G. Mittal, K. Y. Rhee, S.-J. Park, and D. Hui, "A short review on basalt fiber reinforced polymer composites," Composites Part B: Engineering, vol. 73, pp. 166-180, 2015.

[7] C. Colombo, L. Vergani, and M. Burman, "Static and fatigue characterisation of new basalt fibre reinforced composites," Composite Structures, vol. 94, no. 3, pp. 1165-1174, 2012.

[8] M. H. Lapena, G. Marinucci, M. H. Lapena, and G. Marinucci, "Mechanical characterization of basalt and GlassFiber epoxy composite tube," Materials Research, vol. 21, 2017.

[9] G. Wu, X. Wang, Z. Wu, Z. Dong, and G. Zhang, "Durability of basalt fibers and composites in corrosive environments," Journal of Composite Materials, vol. 49, no. 7, pp. 873-887, 2015.

[10] T. Deák and T. Czigány, "Chemical composition and mechanical properties of basalt and glass fibers: a comparison," Textile Research Journal, vol. 79, pp. 645-651, 2009.

[11] R. Raghavendra Rao, S. Pradeep, S. Karthik, K. R. Gopi, and B. S. Shivashankara, "Experimental investigation of effect of hybridization of UHMWPE fibers on the mechanical and physical properties of Basalt fiber reinforced polymer matrix composites," IOP Conference Series: Materials Science and Engineering, vol. 1189, no. 1, Article ID 012025, 2021.

[12] V. Fiore, G. Di Bella, and A. Valenza, "Glass-basalt/epoxy hybrid composites for marine applications," Materials \& Design, vol. 32, no. 4, pp. 2091-2099, 2011.

[13] M. Lilli, M. Zvonek, V. Cech, C. Scheffler, J. Tirillò, and F. Sarasini, "Low temperature plasma polymerization: an effective process to enhance the basalt fibre/matrixinterfacial adhesion," CompositesCxommunications, vol. 27, Article ID 100769, 2021.

[14] G. S. Gangappa, S. S. Kulkarni, "Experimentation and validation of basalt \& jute fiber reinforced in polymer matrix hybrid composites," Materials Today: Proceedings, vol. 38, no. 5, pp. 2372-2379, 2021.

[15] X. Zhao, X. Wang, Z. Wu, and J. Wu, "Experimental study on effect of resin matrix in basalt fiber reinforced polymer 
composites under static and fatigue loading," Construction and Building Materials, vol. 242, Article ID 118121, 2020.

[16] S. Yu, K. H. Oh, and S. H. Hong, "Enhancement of the mechanical properties of basalt fiber-reinforced polyamide 6,6 composites by improving interfacial bonding strength through plasma-polymerization," Composites Science and Technology, vol. 182, Article ID 107756, 2019.

[17] S. S. Kumbar, D. A. Jadhav, C. S. Jarali et al., "Enhancement in cathodic redox reactions of single-chambered microbial fuel cells with Castor oil-emitted powder as cathode material," Materials, vol. 14, no. 16, p. 4454, 2021.

[18] T. H. M. Mysore, A. Y. Patil, G. U. Raju et al., "Investigation of mechanical and physical properties of big sheep horn as an alternative biomaterial for structural applications," Materials, vol. 14, no. 14, p. 4039, 2021.

[19] B. N. Sharath, C. V. Venkatesh, A. Afzal et al., "Multi ceramic particles inclusion in the aluminium matrix and wear characterization through experimental and response surface-artificial neural networks," Materials, vol. 14, no. 11, p. 2895 , 2021.

[20] S. Nagaraja, K. U. Nagegowda, A. V. Kumar et al., "Influence of the fly ash material inoculants on the tensile and impact characteristics of the aluminum AA 5083/7.5SiC composites," Materials, vol. 14, no. 9, p. 2452, 2021.

[21] M. N. Akhtar, M. Khan, S. A. Khan et al., "Determination of non-recrystallization temperature for niobium microalloyed steel," Materials, vol. 14, no. 10, p. 2639, 2021.

[22] S. Nasri, B. Ebrahimi-Hosseinzadeh, M. Rahaie, A. HatamianZarmi, and R. Sahraeian, "Thymoquinone-loaded ethosome with breast cancer potential: optimization, in vitro and biological assessment," Journal of Nanostructure in Chemistry, vol. 10, no. 1, pp. 19-31, 2020.

[23] P. Joshi, S. Mehtab, M. G. H. Zaidi, T. Tyagi, and A. Bisht, "Development of polyindole/tungsten carbide nanocomposite-modified electrodes for electrochemical quantification of chlorpyrifos," Journal of Nanostructure in Chemistry, vol. 10, no. 1, pp. 33-45, 2020.

[24] Z. Amirsardari, A. Dourani, M. A. Amirifar, N. Ghadiri Massoom, and R. Ehsani, "Development of novel supported iridium nanocatalysts for special catalytic beds," Journal of Nanostructure in Chemistry, vol. 10, no. 1, pp. 47-53, 2020.

[25] G. S. N. Rethnam, S. Manivel, V. K. Sharma et al., "Parameter study on friction surfacing of AISI316Ti stainless steel over EN8 carbon steel and its effect on coating dimensions and bond strength," Materials, vol. 14, no. 17, p. 4967, 2021. 